Wilfrid Laurier University

Scholars Commons @ Laurier

\title{
Tweeting about sexism: The well-being benefits of a social media collective action.
}

Mindi D. Foster

Wilfrid Laurier University, mfoster@wlu.ca

Follow this and additional works at: https://scholars.wlu.ca/psyc_faculty

Part of the Psychiatry and Psychology Commons, and the Social Psychology Commons

\section{Recommended Citation}

Foster, Mindi D., "Tweeting about sexism: The well-being benefits of a social media collective action." (2015). Psychology Faculty Publications. 49.

https://scholars.wlu.ca/psyc_faculty/49

This Article is brought to you for free and open access by the Psychology at Scholars Commons @ Laurier. It has been accepted for inclusion in Psychology Faculty Publications by an authorized administrator of Scholars Commons@ Laurier. For more information, please contact scholarscommons@wlu.ca. 


\begin{abstract}
Although collective action has psychological benefits in non-gendered contexts (e.g., Drury et al., 2005), the benefits for women taking action against gender discrimination are unclear. This study examined how a popular, yet unexplored potential form of collective action, namely tweeting about sexism, affects women's wellbeing. Women read about sexism and were randomly assigned to tweet, or to one of three control groups. Content analyses showed tweets exhibited collective intent and action. Analyses of linguistic markers suggested public tweeters used more cognitive complexity in their language than private tweeters. Profile analyses showed that compared to controls, only public tweeters showed decreasing negative affect and increasing psychological well-being, suggesting tweeting about sexism may serve as a collective action that can enhance women's well-being.
\end{abstract}

Keywords: Collective action, confrontation, Twitter, sexism, gender discrimination, linguistic markers, negative affect, well-being 


\section{Introduction}

Research shows that even controlling for demographic factors, experiences of sexism are associated with reduced mental (e.g., depression, lower self-esteem and well-being) and physical health (e.g., pain, addiction, stress-reactive hormones) (see Pascoe \& Smart Richman, 2009; Schmitt, Branscombe, Postmes \& Garcia, 2014 for reviews). Identifying interventions that attenuate these risks is therefore important. The Elaborated Social Identity Model (ESIM; Drury \& Reicher, 1999) provides a theoretical framework for suggesting that collective action against injustice may be such an intervention, capable of enhancing components of well-being, such as efficacy (Bandura, 1982), empowerment (Bennett Cattaneo \& Chapman, 2010; Ryff, 1989), mood and life satisfaction (Diener, 1984), as well as psychological and physical symptomatology (Sherbourne, Aleen, Kamberg \& Wells, 1992). The ESIM argues that by acting in solidarity with other group members, individuals view their actions as effective and therefore feel empowered. Consistent with this, research in non-gendered contexts (taxes, roads, HIV, homophobia) shows that collective action is positively predicts efficacy (Cocking \& Drury, 2004), empowerment (Drury, Cocking, Beale, Hanson \& Rapley, 2005), life satisfaction (Bachmann \& Simon, 2014) and physical/psychological well-being (Molero, Fuster, Jetten \& Moriano, 2011). Experimental work also shows that signing a petition or email protest increases group efficacy (Van Zomeren, Drury \& Van der Staaij, 2012) and positive affect (Becker, Tausch \& Wagner, 2011). Thus, collective action against injustice appears to benefit well-being. 
Research conducted within gendered contexts, however, is less clear. Some actions hinder well-being; reporting more incidents of sexual harassment is related to increased distress (Bergman, Lanhout, Palmieri, Cortina \& Fizgerald, 2002) and healthrelated problems (Hesson-Mclnnis \& Fitzgerald, 1999). Endorsing actions against a sexist experimenter predicts negative mood (Foster, 2009). Indeed, this may not be surprising given women who confront sexism are disliked and viewed as complainers, even by other women (Czopp \& Monteith, 2003; Garcia, Hortsman Reser, Amo, \& Redersdorff \& Branscombe, 2005; Kaiser \& Miller, 2004; Shelton \& Stewart, 2004). Yet, there is also research suggesting that the benefits of collective action against gender discrimination may depend on the particular action. For example, confronting a perpetrator in anger increases well-being over time, whereas educational and indirect confrontations decrease well-being (Foster, 2013). Using email to inform others (Gervais, Hillard \& Vescio, 2010; Foster, 2014) of sexism also increases wellbeing, but may only do so if the discrimination is perceived as pervasive (Foster, 2014). Given gender discrimination can have both positive and negative well-being consequences, identifying which actions will be beneficial for women is of considerable importance.

The most beneficial actions may be those considered by the actor to be active, public and collective; across a variety of actions (informing the media, threatening legal action, meeting with the discriminator), how women define these actions moderates the relationship between participation and well-being (Foster, 2014). Among women who define actions as passive, private and individual, greater endorsement predicts lower well-being. Yet, among women who define the actions as active, public and collective, 
greater endorsement predicts greater well-being. Indeed, across both gendered and non-gendered contexts, the beneficial actions appear to be those that are active (e.g., direct confrontations; Foster, 2013), public (e.g., informing others; Becker et al., 2011) and collective (e.g., government protests; Cocking \& Drury, 2004). Thus, it is important to identify the actions that epitomize those characteristics to assess their benefits for women's well-being.

One such action may be tweeting about sexism. Twitter, among the most used micro-blogging sites ("The top 500 sites", 2014), warrants investigation for at least two practical reasons. First, among Twitter users, 74\% are younger than 25 ("An exhaustive study", 2012), and women use Twitter more than men, both in North America ("An exhaustive study", 2012), and during the Egyptian protests (Tufekci \& Wilson, 2012). Because young women are the predominant users of Twitter, identifying effective tweeting methods may be valuable for enhancing thriving, both socially and psychologically. Moreover, Twitter's practical use has been demonstrated during the revolutionary social movements in the Middle East. For example, analyses of tweets about the 2011 Egyptian government protests showed active tweeting and re-tweeting between bloggers, activists and journalists about the collective purpose played a significant role in informing the world (Lotan, Graeff, Ananny, Gaffney, Pearce \& Boyd, 2011). Not only was the general public using Twitter, but governments have viewed it as such a powerful tool that they either encouraged or threatened its usage. For instance, the U.S. government believed Twitter to be so important during the 2009 Iranian election protests, it requested a rescheduled maintenance shut-down so the information flow could continue (Pleming, 2009), and, in 2014, the Turkish Prime 
Minister vowed to ban Twitter because its ability to mobilize information threatened to de-stabilize his government (Letsch, 2014). Thus, use of Twitter to mobilize information about social injustice has practical value.

Further, using Twitter to mobilize information is consistent with theoretical definitions of collective action. Collective action has been defined as any action that serves to benefit group status, whether it is taken with a group or individually (Wright, 2009). Individual behaviours are considered collective if they are collectively intended, i.e. if thoughts/actions are guided by group rather than personal interests (Louis, 2009; Van Zomeren \& lyer, 2009). A form of collective action that meets these criteria is "consensus mobilization" (Klandermans, 1984) or "persuasive action" (Brunsting \& Postmes, 2002; Postmes \& Brunsting, 2002). Consensus mobilization occurs when "a social movement tries to obtain support for its point of view. It is directed towards influencing knowledge, beliefs and attitudes" (Klandermans, 1984; p. 107). When individuals attempt to inform others that "a certain state of affairs is unacceptable and can be changed" (Klandermans, 1987, p. 519), they are participating in consensus mobilization. Some pre-social media forms of this have included letter writing (Foster \& Matheson, 1995; Klandermans, 1997); signing a petition (Louis, 2009; Kelly \& Breinlinger, 1995) or emailing others (Becker, et al., 2011; Foster, 2014). In the digital age, Twitter use may be a technological variation of consensus mobilization. In turn, if Twitter use serves as a form of collective action, then consistent with the ESIM (e.g., Drury et al., 2005), it may also serve to increase well-being.

The current study therefore examined how Twitter use may benefit women's wellbeing after tweeting about sexism. Given the relationship between confronting sexism 
and well-being varies longitudinally (Foster, 2013), it was expected that any effects would be apparent over time. This is also consistent with the process approach to stress and coping (Lazarus, 1993; Lazarus \& Folkman, 1984), suggesting responses to stressors (i.e., discrimination; Kaiser \& Miller, 2004) change during the coping process and therefore best captured over time. Participants were therefore randomly assigned to either tweet about sexism, or to a control condition, and then completed well-being measures, three days in a row. Consistent with work showing the benefits of informing others (Becker et al., 2011; Foster, 2014), it was expected that women tweeting about sexism would show greater increases in well-being over the three days than those in the control groups.

\section{Methods}

\section{Participants}

Undergraduate women $(N=93, M$ age $=20.56, S D=3.05)$ responded to posters placed at a university in Ontario, Canada: "Twitter users wanted for a research study on how Twitter affects our thoughts and feelings about information we receive. If interested, follow us at ...". Snowball recruiting was also used whereby participants who had completed the study could re-tweet the above statement. $55.9 \%$ of participants came from the local university, $36.6 \%$ came from other universities, and $7.5 \%$ were unknown. Self-reported majors were 29.9\% Arts (e.g., English, Communications), 22.7\% Science (e.g.,Biology, Health Science), 20.6\% Psychology, 13.4\% Business and 13.4\% unknown. Self-reported ethnicity was 48.5\% White/European, 15.5\% South Asian (e.g. East Indian, Pakistani), 17.5\% Asian (Chinese, Japanese, Korean), 5.1\% Southeast Asian (e.g. Cambodia, Philippines), 3.1\% West Indian, 3.1\% Multi-racial, 2.1\% Latin 
American, Black and Arabic, $.9 \%$ unknown. Participants chose either course credit or a $\$ 12$ Starbucks e-card as incentive.

\section{Procedure}

Once participants "followed" the study's twitter account, the research assistant followed participants so that private instructions could be sent using direct messaging. After consenting, participants indicated a preferred participation time so that delays between each step of the procedure (presentation of sexism, tweeting, outcome measures) could be prevented.

On the first of the three days, participants completed demographics and premeasures and were then sent a link via direct messaging that contained articles portraying sexism in the media. In particular, they read how sexual innuendo was made about Condoleeza Rice's clothing (“Condi Rice, Dominatrix, 2005); how female justices are preferred if they are thin (Campos, 2009); and how the media reinforce stereotypes of power women, entitled, "The 'Bitch' and the 'Ditz'”, referring to Hillary Clinton and Sarah Palin (Fortini, 2008).

On day two, sexism in politics was portrayed with three articles: one described how a female politician was called a whore for switching political parties ("Sexism cited", 2005), another quoted a male politician sexualizing a female politician at a professional meeting (“Finance minister", 2007 ), and one documented a politician's blog to girls graduating from seventh grade, "Men are attracted to smiles... if you want equal, it comes in little packages at Starbucks ("Men attracted to smiles, 2009).

On day three, sexism at university was portrayed with three instances of sexism that occurred on a local university campus: a university-approved poster using sex to 
advertise a rental apartment; an undergraduate academic calendar that featured only male professors and students on the front and back covers, and a university newspaper article entitled, "A gentleman's guide to getting laid at WLU" (Weinberg, 2005) which described how, at each year of their university career, young men could use a different technique to seduce the university's "promiscuous" young women.

After completing each day's articles, participants were sent instructions that varied depending on the randomly assigned condition; instructions appear in quotes and participants were told nothing beyond those instructions. Those in the experimental (tweet) condition $(n=23)$ were instructed to "Please tweet about the information you received now". Three control groups were also included. First, to rule out the potential effects due to expressive writing (Pennebaker \& Chung, 2007), some participants ( $n=$ 28) were assigned to tweet privately. Their instructions were to "Please enter and save your tweet below [a text box and save button appeared]. This tweet will not go anywhere. It will be private and confidential". Second, to rule out any effects due to the mere act of tweeting versus tweeting about the relevant content, some participants ( $n=$ 23) were assigned to "Please tweet about a completely different topic, namely the day's weather, now." Finally, those in the no-tweet control condition $(n=19)$ were instructed, "Please do not tweet about the information you received or anything else"; participants in this condition had consented not to tweet for the duration of the study. To maintain ecological validity, the audience for the tweets was not manipulated; participants tweeted as they normally would, namely to their own followers. It should be noted that although instructions did not specify how often participants should tweet, with the 
exception of one tweet (which was broken up into 3 tweets), participants tweeted only one tweet per day.

After each day's tweet, participants received a link containing the outcome measures. Upon completion, participants received debriefing, their incentive, and were asked to "unfollow" the study to maintain privacy.

\section{Measures}

Pre-measures. Given neuroticism (DeNeve \& Cooper, 1998) and social support (Stroebe \& Stroebe, 1996) predict well-being, both were included as potential covariates. Participants completed the neuroticism sub-scale of the NEO Five-Factor Inventory-Short form (e.g., "I see myself as someone who can be tense"; John \& Srivastava,1999). The mean across the eight items was used as the overall score ( $\propto=$ $.78)$.

Three sub-scales from the Berlin Social-Support Scale-English (Schulz \& Schwarzer, 2003) measured social support: perceived available support (e.g., "There are people who truly like me"), need for support (e.g., "When I am down I need someone who boosts my spirits) and support seeking (e.g., In critical situations, I prefer to ask others for advice"). The mean across all the items was used as the overall score $(\propto=.89)$.

Both questionnaires used the same scale, ranging from strongly disagree (1) to strongly agree (5).

Manipulation checks. To ensure sexism was perceived, participants responded to three questions, "How fair are these articles to women"; "How much is the way that these articles depict women, justifiable/legitimate"; and "How sexist are these articles" 
on a scale ranging from "not at all" fair/justifiable/sexist (1) to "extremely" fair/justifiable/sexist (5). Using the same scale, a measure of personal relevance was also included, "How much do these messages about women affect you personally."

Well-being. The mood component of subjective well-being (Diener, 1984) was assessed using selected (due to time constraints) mood adjectives from the Positive and Negative Affect Schedule-Expanded Form (Watson \& Clark, 1994). Using a scale ranging from "very slightly/not at all" (1) to "extremely" (5), participants indicated to what extent they "feel this way, right now". The means across each set of adjectives were used as the overall score for happiness (happy, delighted, cheerful, enthusiastic, excited; Alphas > .83) hostility (angry, disgusted, hostile; Alphas > .75) and sadness (sad, distressed, irritable, upset) (Alphas > .78) scores.

Psychological well-being (Ryff \& Keyes, 1995) was assessed using the 18 item short form scale (e.g., "I have confidence in my opinions, even if they are contrary to the general consensus", "I am quite good at managing the many responsibilities of my daily life"). Using a scale ranging from "very slightly/not at all" (1) to "extremely" (5), participants indicated how much "each statement describes yourself, right now". The average across all items was used for the overall well-being score (Alphas $>.80$ ).

Linguistic Markers. The words individuals choose to convey their meanings provide information about psychological processes and health and well-being (e.g., Pennebaker \& Chung, 2007). As such, linguistic markers were explored as less obtrusive measures of well-being. Tweets about sexism were analyzed using Linguistic Inquiry and Word Count (Pennebaker, Chung, Ireland, Gonzales \& Booth, 2007), a text analysis program calculating the percentage of total number of words for each word 
category. The categories of interest were chosen based on their associations with wellbeing. In particular, cognitive processes (i.e., words such as "cause", "know", "ought"; see Tausczik \& Pennebaker, 2010 for a review) and cognitive complexity in language (i.e., words per sentence, exclusive words such as "but", "without", "exclude") indicate individuals are cognitively processing the event, trying to find meaning in the event. Greater use of cognitive words are linked to better health outcomes (Pennebaker, Mayne \& Francis, 1997; Rivkin, Gustafson, Weingarten \& Chin, 2006; Schwartz \& Drotar, 2004). Moreover, the emotion categories consistent with the self-report measures were assessed: sadness, anger and positive emotion.

\section{Results}

\section{Manipulation checks}

For sexism to have been successfully portrayed, participants should report scores below the midpoint on fairness and justifiability (perceived unfairness and unjustifiable depictions of women) and above the midpoint on sexism (high perceived sexism). One-sample t-tests showed that all scores were significantly different than the midpoint of the scale (3), MsFaimess $<1.52, S D s<.84$, ts $(78)>27.43, p s=.0001$; MsJustifiable $<1.66, S D s<.91, t \mathrm{~s}(78)>22.94, p s=.0001, M s_{\text {sexism }}>3.92, S D s=<1.03$, ts $(78)>8.41, p s=.0001$. Thus, participants perceived all types of sexism to be unfair, unjustifiable, and sexist.

Moreover, given logistical constraints of the study, the types of sexism were not randomized but rather sexism in media, politics and university were presented on day one, two, and three respectively. As such, it was important to ensure that each type was perceived to be equally unfair, unjustifiable, sexist and personally relevant across days 
and conditions so that any changes would be attributed to time or condition rather than differences in content. For all measures, there were no differences across conditions, $F_{\text {Fairness }}(3,75)=.48, p=70 ; F_{\text {Justifiable }}(3,75)=.26, p=.86 ; F_{\text {sexism }}(3,75)=1.12, p=.31$; $F_{\text {Personal relevance }}(3,75)=.40, p=.89$; no differences across days, $F_{\text {Fairness }}(2,74)=1.06, p$ $=.35 ; F_{\text {Justifiable }}(2,74)=1.61, p=.21 ; F_{\text {sexism }}(2,74)=.27, p=.76 ; F_{\text {Personal relevance }}(2,74)=$ $1.79, p=.17$; nor were there significant condition by day interactions, $F_{\text {Fairness }}(6,148)=$ $1.24, p=.29 ; F_{\text {Justifiable }}(6,148)=.43, p=.86 ; F_{\text {sexism }}(6,148)=1.71, p=.12 ; F_{\text {Personal }}$ relevance $(6,148)=.73, p=.63$. Thus, women perceived the content equally across all days and conditions in terms of fairness, justifiability, sexism and personal relevance, suggesting any differences would not be due to differences in content.

\section{Tweet content}

To explore tweet content in the experimental (public tweet) and private tweet conditions, grounded-theory techniques were used, whereby themes are allowed to emerge from the data (Corbin \& Straus, 2008). To develop coding schemas, a research assistant read and summarized the tweets using 'data-based phrases' ('in vivo' coding), namely words/phrases used by participants themselves, so that data accurately reflect the reality of participants. For example, "I hate gender stereotypes and generalizations. As far as women get, it seems the glass ceiling is always above them" was summarized as "hate stereotypes", "always glass ceiling". Then, comparative analysis was used for axial coding whereby phrases are constantly compared to each other for conceptual similarities and differences; phrases that share conceptual similarities are then grouped together to form a category. For example, the two data-based phrases described above ("hate stereotypes", "always glass ceiling") are conceptually similar in that they both 
describe a problem faced by women. Once the categories had been established, two different research assistants read through the tweets to assign the category codes. The same techniques were used to develop each of three different coding schemas: emotion, collective intent, and consensus mobilization.

Six participants in the private tweet condition and one in the public tweet condition however, ignored instructions to tweet about what they had read and instead tweeted irrelevant information (e.g., "First tweet!") or incorrect information ("An article from CNN"), thus these tweets were not included in analyses.

Emotion. Tweets were assigned one of seven emotion codes that appeared to emerge from the data $(K=.88, p=.0001)$. Because some tweets included two emotions $(26 \%)$, this was repeated for a second emotional theme $(k=.91, p=.0001)$. Three of the identified emotions were anger-based: anger, discontent and sarcasm. $26 \%$ of the tweets were coded as angry ("Never knew there was this much sexism in politics! It's so disturbing! Shocked disgusted"). Discontent (23.3\%), although a form of anger, was coded separately as it appeared to involve a lesser degree of anger (e.g., "Women are more than just sex symbols. Cord [the university newspaper] needs better writers"). $8.2 \%$ of the tweets were sarcastic ("Administration approves degrading ad, Wilfs tricksof-the-trade is "sound advice," and female Profs don't exist. I'll take 'Headlines from 1910' for 800 dollars").

$24.7 \%$ were coded as shocked or surprised ("It's shocking how we don't notice this images until someone points it out"). $11 \%$ of the tweets were coded as sadness ("Those ads were so disturbing! Makes me sad"). $4.1 \%$ of the tweets were coded as content ("Maybe women just need to be a little more lighthearted? Nice legs is a 
compliment"). Finally, some tweets (2.7\%) were coded as no emotion, as none could be discerned ("In politics, both men and women are subjected to name-calling. It just happens to be easier to target women based on their body image").

Of the tweets featuring two emotions, the most common combination was surprise and discontent (52.6\%).

Collective intent. Given the conceptual definition of collective action is that the action shows collective intent (Tajfel \& Turner, 1986; Wright, 2009; Van Zomeren \& lyers 2009), tweets were coded as having collective intent if they referred to group status, identity or interests. A code of 1 (collective intent present) or 0 (none present) was given $(K=.80, p=.0001)$. For example, tweets with collective intent included: "Women and men should be considered and judged equally based on their ability and education. Its too bad that strong, powerful women are taken down in the media based on their clothing choices"; "It is disgusting how we are oppressed in this century after so many women have made it to the same level as men...so much for equality"; "Politics are so sexist towards women. I though we had gotten over this kind of a thing unfair unimpressed". The vast majority of tweets $(90.4 \%)$ referred to women's issues/experiences/status, implying collective intent. The remaining tweets were coded as having no collective intent because it was unclear whether participants were referring to women in particular (e.g., "politics is something!"; "It seems like our society always puts judgements on people of power even when they do a good job").

Cons ens us Mobilization. Consensus mobilization appeared to emerge from the data in four ways: naming the problem; criticizing; persuading and suggesting change. Each tweet was coded for each of the four themes; interrater reliabilities for the 
four components $(\mathrm{k})$ ranged from .80 to $1.0, \mathrm{ps}<.0001$. Tweets received a code of 1 (consensus mobilization present) or 0 (none present).

The most common theme in the tweets was labelled "Naming the problem" (90.4\% of the tweets), consistent with most basic component of consensus mobilization, namely identifying the particular state of affairs the collective wants to change. Example tweets included "Ever notice how powerful women are portrayed in a negative light in the media? I care about ideas, not what your wearing" and "It's disgusting to see people still demean women with words, even worse they don't think they've done anything wrong".

$87.7 \%$ of the tweets were labelled as "Criticizing" consistent with another component of consensus mobilization, indicating disapproval of said state of affairs. For example, the above tweets also received the criticizing codes for the phrases, "I care about ideas not what you're wearing", and "It's disgusting". Most tweets that named the problem also criticized it ( $80.8 \%)$, thereby reflecting the primary goal of consensus mobilization, to inform others that the current state of affairs is unacceptable (Klandermans, 1987). Fewer (6.8\%) tweets criticized but did not name the problem: “This is just sad, can't believe I have a similar university level education as these people".

$52.1 \%$ of the tweets were classified as "persuading" (Postmes \& Brunsting, 2002) in that they appeared to go a step beyond the tweets that named and criticized only. Instead, women appeared to strengthen their argument that the state of affairs is unacceptable by integrating novel information that did not appear in the presented articles. For example, after reading about how women are treated in politics, one 
woman tweeted "Once again, some men are pigs. If you are willing to say that about one woman, are you willing to say that same about your mom if she was in the same position? Show some respect". Another woman, after reading about media portrayal of women made the effort to find additional documentation of women's poor treatment, and used a hashtag so that others could find this information: "Do women with power in business need to be viewed as "ice queens" in order to achieve success? \#stereotypes http://www.forbes.com/sites/jennagoudreau/2011/10/24/worst-stereotypes-powerfulwomen-christine-lagarde-hillary-clinton/". $41.1 \%$ of tweets included all of naming, criticizing and persuading.

Finally, consistent with the goal of mobilizing support for change, tweets were coded as "suggesting change" (12.3\%) if some action or change was requested or described (e.g., "If we truly want to achieve full equality, then we need to fight, just as women before us did."). $6.8 \%$ of tweets included all four responses. Only a few tweets included re-tweeted information (3.5\%).

To test the assumption that tweeting about sexism would be used as a collective action, an overall consensus mobilization score was computed by summing across the four components; scores could range from 0 to 4 . The same profile analysis (described below) used for the quantitative data was used to test if tweeters were using consensus mobilization equally across the public and private tweeting conditions, and days. No significant effects were found, Fs $<1.91$, ps $>.17$, indicating that tweeting about sexism was used as a collective action equally so across days, for both public and private tweeters.

\section{Main analyses}


The experimental design, a 4(condition) $\times 3$ (day) mixed model with repeated measures on the second factor, was tested using a profile analysis (the multivariate approach to repeated measures), because it is robust against unequal sample sizes, provides more power in smaller samples and is recommended when time is the withinsubjects variable (Tabachnik \& Fidell, 2007). Akin to the univariate mixed model ANOVA, profile analysis provides three tests. The levels test assesses whether there are differences between the groups averaged across time points (i.e. the betweensubjects effect); the flatness test assesses whether there are differences across the time points (i.e. the within-subjects effect); the parallelism tests assesses whether changes across the time points differ between groups (i.e. the interaction between the between and within-subjects factors). Tweet condition was the between-groups variable and the within-subjects variables were hostility, sadness, happiness and psychological well-being, each measured three times. Neuroticism and social support were used as potential covariates. Only one covariate effect was significant, namely the effect of neuroticism on hostility, thus it was maintained in that analysis. All other non-significant covariates were removed (Engqvist, 2005).

Hostility (see Figure 1). The interaction between condition and neuroticism on hostility was significant, indicating the slope of neuroticism varied between groups $F(2,87)=3.66, p=.03, \eta_{\mathrm{p}}^{2}=.04$, power $=.66$, thus neuroticism was maintained as a covariate. The levels test was not significant, indicating no main effect for condition, $F(3,88)=2.10, p=.11$. The flatness test, which tests the within-subjects effect for daily hostility, was only marginally significant $F(2,176)=1.96, p=.06, \eta_{p}^{2}=.03$. This was qualified however, by a significant parallelism test, which tests the interaction between 
the between and within-subjects factors; changes in hostility varied across conditions, $F(6,176)=2.85, p=.01, \eta_{p}^{2}=.09$, power $=.88$.

Simple effects analysis within groups showed no daily changes within the control conditions, $F \mathrm{~S}<2.41, p s>.72$. There were, however, changes in hostility within the public tweeting condition, $F(2,178)=5.08, p=.01, \eta_{\mathrm{p}}^{2}=.23$, power $=.88$, such that public tweeters were less hostile on day 3 than day $1, F(1,22)=12.27, p=.002, \eta_{p}^{2}=$ .36 , power $=.92$ and day $2, F(1,22)=7.16, p=.014, \eta_{p}^{2}=.25$, power $=.73$. There were no differences between the first two days on hostility, $F(1,22)=.12, p=.74$.

Simple effects analysis between groups showed differences on day one, $F(3,89)$ $=3.39, \mathrm{p}=.02, \eta_{\mathrm{p}}^{2}=.10$, power $=.75$ and day two, $F(3,89)=3.02, \mathrm{p}=.03, \eta_{\mathrm{p}}^{2}=.09$, power $=.69$ such that public tweeters were more hostile than all the control groups combined on both day three, $t(89)=-2.55, p=.01$ and day $2, t(89)=2.61, p=.01$. By day three, differences in hostility were gone, $F(3,89)=.88, p=.46$.

Sadness (see Figure 2). For sadness, sphericity was violated, thus Greenhouse-Geisser corrections were used. The levels test was not significant, indicating no main effect of condition on sadness, $F(3,89)=1.14, p=.34$. Although the test of flatness was significant, $F(1.84,164.10)=4.71, p=.01, \eta_{p}^{2}=.05$, power $=.78$, this within-subjects main effect was qualified by a significant parallelism test, indicating these changes in sadness varied across groups, $F(5.53,164.10)=2.78, p=.02, \eta_{p}^{2}=$ .09 , power $=.85$.

Simple effects analyses within groups showed no daily changes within the control groups, $F s<3.10, p s>.07$ but there were changes among public tweeters, $F(1.70$, 37.38) $=9.49, p=.001, \eta_{p}^{2}=.30$, power $=.95$. In particular, public tweeters showed 
less sadness on day three compared with both day one, $F(1,22)=12.05, p=.002, \eta_{\mathrm{p}}^{2}=$ .35 , power $=.91$ and day two, $F(1,22)=11.43, p=.003, \eta_{p}^{2}=.34$, power $=.90$. There were no differences in sadness across days one and two, $F(1,22)=.19, p=.67$ among public tweeters. Simple effects analyses between groups showed no significant group differences within either day, Fs $<2.58, p s>.06$.

Happiness. Neither the levels, $F(3,89)=1.65, p=.18$, flatness, $F(1.74,154.52)$ $=1.43, p=.24$, nor the parallelism test, $F(5.21,154.52)=.72, p=.61$ were significant.

Psychological well-being (see Figure 3). Sphericity was violated, thus, Greenhouse-Geisser corrections were used. Neither the levels, $F(3,89)=.60, p=.62$, nor the flatness test was significant, $F(1.86,165.34)=.51, p=.59$, indicating no main effects for either condition or daily well-being. The parallelism test was significant, indicating there were changes in daily well-being that varied across groups, $F(5.57$, 165.34) $=2.20, p=.03, \eta_{\mathrm{p}}^{2}=.09$, power $=.87$.

Simple effects analyses within groups showed no changes among the control groups, $F s<.68, p s>.51$, but there were changes among public tweeters, $F(1.96$, $43.01)=7.87, p=.001, \eta_{\mathrm{p}}^{2}=.26$, power $=.94$. In particular, public tweeters reported greater well-being on day three than on both day one, $F(1,22)=12.97, p=.002, \eta_{p}^{2}=$ .37 , power $=.93$ and day two, $F(1,22)=8.88, p=.01, \eta_{p}^{2}=.29$, power $=.81$. There were no changes across the first two days, $F(1,22)=1.12, p=.30$.

Simple effects analyses between groups showed no significant differences on day $1, F(3,89)=.92, p=.43$ or day $2, F(3,89)=.36, p=.79$, but by day three there were significant differences, $F(3,89)=3.11, p=.03, \eta_{p}^{2}=.10$, power $=.71$ such that public 
tweeters reported greater well-being than all the control groups combined, $t(89)=-2.84$, $p=.006$

Linguistic markers. Consistent with Pennebaker et al., (1997) the average word use across the three days was calculated. T-tests indicated that public tweeters used more cognitive processing words $(M=18.7, S D=8.75)$, words per sentence $(M=$ $19.29, S D=6.14)$ and more exclusive words $(M=3.13, S D=3.18)$ than private tweeters $\left(M_{\text {cognitive processing }}=12.04, S D=9.08\right), t(49)=2.65, p=.01,\left(M_{\text {words } / \text { sentence }}=\right.$ 11.74, $S D=11.74), t(49)=3.74, p=.0001, M$ exclusive $=1.34, S D=2.69), t(49)=2.17, p$ $=.03$ suggesting public tweeters were cognitively processing the information more so, and with greater cognitive complexity than private tweeters.

Consistent with the self-report measure of sadness, public tweeters used fewer sad words $(M=0, S D=1.17)$ than private tweeters $(M=1.17, S D=2.94), t(27)=-2.12$, $p=.04$. Although consistent with the self-report measure, the mean difference between public tweeters $(M=.86, S D=1.75)$ and private tweeters $(M=1.2, S D=2.75)$ on anger words appear to be, this difference was not significant, $t(49)=-.50, p=.62$, nor was the difference between public $(M=4.09, S D=3.61)$ and private tweeters $(M=4.25, S D=$ 7.51) on positive emotion words, $t(49)=-.10, p=.93$.

\section{Discussion}

It was argued that using Twitter as a collective action may enhance women's well-being after being exposed to sexism. Despite receiving no instruction regarding the content of tweets, content analyses confirmed that women asked to tweet about sexism were indeed tweeting in collective ways. Consistent with the definition of collective action (Klandermans, 1987; Wright, 2009), both public and private tweets exhibited 
collective intent and attempts to mobilize consensus that sexism is wrong. This is also consistent with the Rejection Identification Model (Branscombe, Schmitt \& Harvey, 1999) which shows that recognizing sexism can serve to make the collective salient; given sexism was recognized equally across conditions and time, this finding is reasonable.

Nevertheless, the fact that private tweets also reflected collective action, raises the question of whether a private behaviour can be a collective action without a public audience. Collective action theorists note that collective actions do not require "physical and temporal proximity of members" (Louis, 2009, p. 727) and "can be engaged in by a single individual acting alone" (Wright, 2009, p. 861). As such, private individual behaviours like voting, or gathering information about group status have been used as operational definitions of collective action (e.g., Foster \& Matheson, 1995; Louis, 2009). Thus, private tweeters may have exhibited collective action despite not having an audience, perhaps to prepare for future action; this is consistent with process perspectives on collective action which argue that definitions of collective action should include not just the final action but those leading up to it as well (Bowles \& Duelli Klein, 1983; Lalonde \& Cameron, 1994). At the same time however, it may be unlikely that private collective action would be perceived as effective. Hornsey et al. (2006) showed that endorsing future collective action is less likely among those who perceive the action to be ineffective in influencing the public. Thus, if private tweeters perceived their tweets as ineffective in influencing the public, then it may not be surprising that continuing such action would not increase well-being; instead, having to do so may have been considered a daily hassle. This is consistent with past work showing that not just any 
collective action is empowering, but rather it is the collective actions perceived to be effective at advancing the aims of the collective that increase empowerment (Drury et al., 2005) and moderate emotional consequences of collective action participation (Tausch \& Becker, 2013).

The other control groups also showed no changes in well-being. Consistent with work showing the benefits of acting versus doing nothing (Becker et al., 2011; Foster, 2014), inaction did not benefit well-being, given the lack of change in the no-tweet control group. Nor did the mere act of tweeting about anything benefit well-being, given the lack of changes for weather tweeters. Finally, there was no significant effect on happiness, this is consistent with Schmitt et al.'s (2014) meta-analysis, showing that discrimination effects on positive affect are weaker than for negative affect.

Instead, consistent with work showing the benefits of public action (Foster, 2013, 2014), tweeting when their followers would read the tweets increased well-being and decreased negative affect. Thus, although private expressive writing is beneficial for improving health after individual traumas (e.g., Pennebaker \& Chung, 2007), negative experiences that affect a whole group may require a response that can potentially reach that group in order to reap the well-being benefits. As differences in word usage suggested, public tweeters appeared to have cognitively processed the information to a greater extent than private tweeters. Having to face the consequences when one's views are put into the public may encourage greater attempts to understand and make meaning of the information. This is consistent with work showing greater self-concept change from public versus private behaviours (Tice, 1992). 
Granted, not all public confrontations under all circumstances will be beneficial. For instance, when confronting in anger, well-being increases over time whereas politely educating a perpetrator decreases well-being (Foster, 2013). Thus, future research should examine the conditions under which public tweeting may and may not be beneficial. For example, it is conceivable that tweeting to one's followers about work frustrations if those followers include work colleagues may involve negative consequences and as such, may not benefit well-being.

Although tweeting about sexism enhanced psychological well-being and decreased sadness over time, the pattern for hostility differed; public tweeters were more hostile the first two days than control groups, but their hostility declined by the last day. Thus, the question remains whether tweeting made women more hostile initially, an effect that would decrease over time, or whether tweeting gave women the opportunity to express their anger about inequality. Even if tweeting did increase women's initial hostility, they may not have been experiencing self-directed hostility (which would decrease well-being) but rather, hostility directed at the outgroup. This would be consistent with the study by Becker et al., (2011) showing collective action leads to increased anger directed at the outgroup, and simultaneous self-directed positive affect. As such, the findings in the current study whereby tweeting led to greater hostility initially but also increasing well-being may not be surprising; women may have felt angry with perpetrators of sexism, but felt good about themselves after doing something about it. Thus, future studies will not only need to include baseline and posttweet measures of hostility but also delineate each in terms of self versus outgroup directed affect. 
Future research should also include measures of collective emotions. It could be argued, given the positive relationship between anger and collective action (see Van Zomeren et al., 2008 for a review), that if tweeting about sexism lowers hostility toward the outgroup over time, then it will not be useful in motivating future activism. However, as data supporting the ESIM (Drury \& Reicher, 1999) show, there are alternative paths to collective action through positive emotions such as collective pride and joy (Drury, Evripidou \& Van Zomeren, in press; Drury et al., 2005; Tausch \& Becker, 2013) and initial collective action itself (Becker et al., 2011). Thus, even if tweeting about sexism were to reduce hostility toward the outgroup over time, its positive well-being effects as well as the act having previously tweeted about sexism may motivate future activism.

A limitation of the current study is that the lack of counterbalancing of sexism primes presents an alternative explanation, namely that well-being increased as a function of tweeting about university-specific information, rather than time itself. However, that explanation is less plausible given all three primes were perceived equally in terms of sexism, unfairness, illegitimacy and personal relevance. Thus, given the primes did not differ in content, and moreover, that past research has shown the relationship between confronting sexism and well-being varies over time (Foster, 2013), it may be more reasonable to conclude that in this study, well-being varied as a function of time instead of content.

Moreover, this study did not assess potential moderators. For example, type of sexism affects tendency to confront (Ayres, Friedman \& Leaper, 2009) but this study only examined institutional sexism. Whether tweeting about personal experiences of sexism or even other forms of injustice, will also buffer negative health effects of 
discrimination remains to be seen. Moreover, identity should be assessed in future work; the Rejection Identification model (e.g., Branscombe, et al., 1999; Schmitt, Branscombe, Kobrynowicz \& Owen, 2002) has shown that group identity is also protective of well-being. As such, tweeting about sexism may be especially beneficial among high identifiers. Finally, it is possible that Twitter could also be used in ways that are detrimental to well-being. For example, in this $24 / 7$ information era, the potential for information overload exists. Twitter followers of social movements such as everydaysexism.com receive repeated alerts of women's everyday experiences with gender discrimination. As passive followers (i.e., where they only read this information), they may be at risk; the more women search out information about sexism, the more despair they feel (Stroebe, Barretto \& Ellemers, 2010). The current study suggests however, that if Twitter is used more actively, i.e., tweeting out responses to that information, women may be buffered from the negative effects of repeated exposure.

Despite its limitations however, this study is unique compared to many other Twitter studies have focused only observational/field techniques to assess the content of tweets (e.g., Bae \& Lee, 2012; Ritter, Preston \& Hernandez, 2013; Tumasjan et al., 2011). In contrast, this study combined the benefits of both experimental and field techniques with the goal of enhancing internal and external validity. As such, the causal impact of tweeting about sexism could be assessed without fully sacrificing how tweeting actually occurs outside the lab. Moreover, given the ubiquitous nature of Twitter, especially for young women ("An exhaustive study, 2012; Tufekci \& Wilson, 2012), the results of this study suggest that tweeting about sexism may be an effective 
and easily accessible tool for reducing the negative health consequences of gender discrimination (e.g., Pascoe \& Smart Richman, 2009).

Although online activism has been criticized as merely "slacktivism", namely behaviours that have no impact other than to make people feel good about themselves (Mozorov, 2009), such a criticism underestimates the power that positive psychological consequences may have on motivating future collective action. Indeed, the benefit of positive consequences is well-documented; behaviours that are followed by positive consequences are repeated (Skinner, 1971). Similarly, as evidence supporting the ESIM (Drury, et al., in press; Drury et al., 2005; Tausch \& Becker, 2013) shows, feeling positive after taking collective action can motivate future action. Although such studies did not explicitly examine online activism, there is evidence that on- and offline activism are related. Both activists and non-activists view both on- and offline actions to be equally effective (Postmes \& Brunsting, 2002; Brunsting \& Postmes, 2002). Further, online activism predicts offline collective intentions (Brunsting \& Postmes, 2002) and offline collective actions (Conroy, Feezell, Guerrero, 2012; Vitak, Zube, Smock, Carr, Ellison \& Lampe, 2011). Thus, understanding how people feel after online activism may be an important first step to motivating future and additional forms of collective action.

\section{References}

"An exhaustive study of Twitter users across the world". beevolve.com Retrieved May 24, 2014 from http://www.beevolve.com/twitter-statistics/\#a2

Ayres, M. M., Friedman, C. K., \& Leaper, C. (2009). Individual and situational factors related to young women's likelihood of confronting sexism in their everyday lives. 
Sex Roles, 61, 449-460. DOI 10.1007/s11199-009-9635-3

Bachmann, A. S., \& Simon, B. (2014). Society matters: The meditational role of social recognition in the relationship between victimization and life satisfaction in gay men. European Journal of Social Psychology, 44, 195-201. DOI:

10.1002/ejsp.2007

Bae, Y. \& Lee, H. (2012). Sentiment analysis of twitter audiences: Measuring positive or negative influence of popular twitterers. Journal of the Association for Information Science and Technology, 63, 2521-2535. DOI: 10.1002/asi.22768

Bandura, A. (1982). The assessment and predictive generality of self-precepts of efficacy. Journal of Behavior Therapy and Experimental Psychiatry, 13, 195-199.

Becker, J. C., Tausch, N. Wagner, U. (2011). Emotional consequences of collective action participation: Differentiating self-directed and outgroup-directed emotions. Personality and Social Psychology Bulletin, 37, 1587-1598. DOI: $10.1177 / 0146167211414145$

Bennett Cattaneo, L., \& Chapman, A. R. (2010). The process of empowerment. A model for use in research and practice. American Psychologist, 65, 646-659. DOI: $10.1037 / \mathrm{a} 0018854$

Bergman, M., Lanhout, R.D., Palmieri, P. A., Cortina, L. M., \& Fitzgerald, L. F. (2002). The (un) reasonableness of reporting: antecedents and consequences of reporting sexual harassment. Journal of Applied Psychology, 87, 230-242. DOI: $10.1037 / / 0021-9010.87 .2 .230$

Branscombe, N. R., Schmitt, M. T., \& Harvey, R. D. (1999). Perceiving pervasive 
discrimination among African-Americans: Implications for group identification and well-being. Journal of Personality and Social Psychology, 77, 135-149.

DOI:10.1037//0022-3514.77.1.135

Bowles, G. \& Duelli Klein, R. (1983). Theories of women's studies. London, England: Routledge.

Brunsting, S., \& Postmes, T. (2002). Social movement participation in the digital age: Predicting offline and online collective action. Small Group Research, 33, 525554. DOI: $10.1177 / 104649602237169$

Campos, P. (2009). Fat judges need not apply. Retrieved from July 2013 from http://www.thedailybeast.com/articles/2009/05/04/fat-judges-need-not-apply.html

Cocking, C., \& Drury, J. (2004). Generalization of efficacy as a function of collective action and intergroup relations: Involvement in an anti-roads struggle. Journal of Applied Social Psychology, 34, 417-444. DOI: 10.1111/j.1559-

1816.2004.tb02555.x

Condi Rice, Dominatrix (2005). Retrieved July, 2013 from http://www.bongonews.com/layout3.php?event=1665

Corbin, J., \& Strauss, A. (2008). Basics of qualitative research (3rd ed.). Los Angeles, CA: Sage.

Conroy, M., Feezell, J. T., \& Guerrero, M. (2012). Facebook and political engagement: A study of online political group membership and offline political engagement. Computers in human behavior, 28, 1535-1546. DOI:10.1016/j.chb.2012.03.012

Czopp, A., \& Monteith, M. J. (2003). Confronting prejudice (literally): Reactions to confrontations of racial and gender bias. Personality and Social Psychology 
Bulletin, 29, 532-544. DOI: 10.1177/0146167202250923

Diener, E. (1984). Subjective well-being. Psychological Bulletin, 95, 542-575.

DeNeve, K. M. \& Cooper, H. (1998). The happy personality: A meta-analysis of 137 personality traits and subjective well-being. Psychological Bulletin, 124, 197-229. DOI:10.1037/0033-2909.124.2.197

Drury, J., Cocking, C., Beale, J., Hanson, C., \& Rapley, F. (2005). The phenomenology of empowerment in collective action. British Journal of Social Psychology, 44, 309328. DOI: $10.1348 / 014466604 \times 18523$

Drury, J., Evripidou, A., \& Van Zomeren, M., (in press). Empowerment: The intersection of identity and power in collective action. In D. Sindic, M. Barreto, and R. C. Lopes. Psychology Press.

Drury, J., \& Reicher, S. (1999). The intergroup dynamics of collective empowerment: Substantiating the social identity model. Group Processes and Intergroup Relations, 2, 381-402. DOI: 10.1177/1368430299024005

Engqvist, L. (2005). The mistreatment of covariate interaction terms in linear model analyses of behavioural and evolutionary ecology studies. Animal Behaviour, 70, 967-971. DOI:10.1016/j.anbehav.2005.01.016

Finance minister under fire for 'sexist' comments (2007). Niagrafallsreview.ca. Retrieved July, 2013 from http://www.niagarafallsreview.ca/2007/11/17/finance-ministerunder-fire-for-sexist-comments.

Fortini, A. (2008). The "Bitch" and the "Ditz": How the Year of the Woman reinforced the two most pernicious sexist stereotypes and actually set women back. Newyorkmag.com. Retrieved July 2013, from 
http://nymag.com/news/politics/nationalinterest/52184/

Foster, M.D. (2009). Perceiving pervasive discrimination over time: Implications for coping. Psychology of Women Quarterly, 33, 172-182. DOI: 10.1111/j.14716402.2009.01487.x

Foster, M. D. (2013). The personal costs and benefits of responding to discrimination: Behavioral responses and well-being over time. International Journal of Psychological Studies, 5, 135-154. DOI: 10.5539/ijps.v5n3p135

Foster, M. D. (2014). The relationship between collective action and well-being and its moderators: pervasiveness of discrimination and dimensions of action. Sex Roles, 70, 165-182. DOI 10.1007/s11199-014-0352-1

Foster, M. D. \& Matheson, K. (1995). Double relative deprivation: Combining the personal and political. Personality and Social Psychology Bulletin, 21, 1167-1177. DOI: $10.1177 / 01461672952111005$

Garcia, D.M., Horstman Reser, A., Amo, R.B., Redersdorff, S., \& Branscombe, N.R. (2005). Perceivers' responses to in-group and out-group members who blame a negative outcome on discrimination. Personality and Social Psychology Bulletin, 31, 769-780. DOI: $10.1177 / 0146167204271584$

Gervais, S. J., Hillard, A. L., \& Vescio, T. K. (2010). Confronting sexism: The role of relationship orientation and gender. Sex Roles, 63, 463-474. DOI $10.1007 / \mathrm{s} 11199-010-9838-7$

Hesson-McInnis, M. S., \& Fitzgerald, L. F. (1997). Sexual harassment: A preliminary test of an integrative model. Journal of Applied Social Psychology, 27, 877-901. DOI: 10.1111/j.1559-1816.1997.tb00276.x 
Hornsey, M. J., Blackwood, L., Louis, W., Fielding, K., Mavor, K., Morton, T., O’Brien, A. et al. (2006). Why do people engage in collective action? Revisiting the role of perceived effectiveness. Journal of Applied Social Psychology, 36, 1701-1722. DOI: $10.1111 / j .0021-9029.2006 .00077 . x$

John, O. P., \& Srivastava, S. (1999). The Big five trait taxonomy: History, measurement and theoretical perspectives. In L. A. Pervin \& O. P. John (Eds.), Handbook of personality, theory and research (pp. 102-138). New York: Guilford.

Kaiser, C. R., \& Miller, C. T. (2004). A stress and coping perspective on confronting sexism. Psychology of Women Quarterly, 28, 168-178. DOI: 10.1111/j.14716402.2004.00133.x

Kelly, C., \& Breinlinger, S. (1995b). Identity and injustice: Exploring women's participation in collective action. Journal of Community and Applied Social Psychology, 5, 41-57. DOI: 10.1002/casp.2450050104

Klandermans, P. G. (1984). Mobilization and participation in trade union action: An expectancy-value approach. Journal of Occupational Psychology, 57, 107-120. DOI: 10.1111/j.2044-8325.1984.tb00153.x

Klandermans, B. (1987). Potentials, networks, motivations and barriers: Steps towards participation in social movements. American Sociological Review, 52, 519-531. DOI: $10.2307 / 2095297$

Klandermans, B. (1997). The social psychology of protest. Oxford: Blackwell Publishers. Lalonde, R. N., \& Cameron, J. E. (1993). Behavioral responses to discrimination: The focus on action. In M. P. Zanna \& J. M. Olson (Eds.), The Ontario Symposium (Vol. 7, pp. 257-288). Hillsdale, NJ: Erlbaum. 
Lazarus, R. S. (1993). Coping theory and research: Past, present and future.

Psychosomatic Medicine, 55, 234-247. DOI: 10.1097/00006842-199305000-00002

Lazarus, R. S., \& Folkman, S. (1984). Stress, appraisal and coping. New York, NY: Springer.

Letsch, C. (March, 2014). Turkey Twitter users flout Erdogan ban on micro- blogging site. The Guardian. Retrieved from http://www.theguardian.com/world/2014/mar/21/turkey-twitter-users-flout-banerdogan

Lotan, G., Graeff, E., Ananny, M., Gaffney, D., Pearce, I., \& Boyd, D. (2011). The revolutions were tweeted: Information flows during the 2011 Tunisian and Egyptian revolutions. International Journal of Communications, 5, 1375-1405.

Louis, W. R. (2009). Collective action-Then what? Journal of Social Issues, 65, 727748. DOI: $10.1111 /$ j.1540-4560.2009.01623.x

'Men attracted to smiles', Alberta MLA advised girls on blog. Cbc.ca. Retrieved July 2013 from http://www.cbc.ca/news/canada/edmonton/men-are-attracted-to-smilesalberta-mla-advised-girls-on-blog-1.808496

Molero, F., Fuster, M. J., Jetten, J., \& Moriano, J. A. (2011). Living with HIV/AIDS: A Psychosocial perspective on coping with prejudice and discrimination. Journal of Applied Social Psychology, 41, 609-626.

Morozov E. The brave new world of slacktivism. Foreign Policy, May 19, 2009. Retrieved May 18, 2014 from http://neteffect.foreignpolicy.com/posts/2009/05/19/the_brave_new_world_of_slack tivism?wp_login_redirect $=0$ 
Pascoe, E. A., \& Smart Richman, L. (2009). Perceived discrimination and health: A meta-analytic review. Psychological Bulletin, 135, 531-554. DOI: $10.1037 / \mathrm{a} 0016059$

Pennebaker, J.W., \& Chung, C.K. (2007). Expressive writing, emotional upheavals, and health. In H. Friedman and R. Silver (Eds.), Handbook of health psychology (pp. 263-284). New York: Oxford University Press.

Pennebaker, J. W., Chung, C. K., Ireland, M., Gonzales, A., \& Booth, R. J. (2007). The development and psychometric properties of LIWC2007. Austin, Texas, USA: LIWC.net

Pennebaker, J. W., Mayne, T. J., \& Francis, M. E. (1997). Linguistic predictors of adaptive bereavement. Journal of Personality and Social Psychology, 72 , 863-871. DOI: 10.1037//0022-3514.72.4.863

Pleming, S (June, 2009). U.S. State department speaks to Twitter over Iran. Reuters. Retrieved from http://www.reuters.com/article/2009/06/16/us-iranelection-twitter-usa-idUSWBT01137420090616

Postmes, T., \& Brunsting, S (2002). Collective action in the age of the internet: Mass communication and online mobilization. Social Science Computer Review, 20, 290-301. DOI: $10.1177 / 08939302020003006$

Ritter, R. S., Preston, J. L., \& Hernandez, I. (2014). Happy tweets: Christians are happier, more socially connected, and less analytical than atheists on Twitter. Social Psychological and Personality Science, 5, 243-239. DOI:

$10.1177 / 1948550613492345$

Rivkin, I. D., Gustafson, J., Weingarten, I., \& Chin, D. (2006). The effects 
of expressive writing on adjustment to HIV. AIDS and Behavior, 10, 13-26. DOI: 10.1007/s10461-005-9051-9

Ryff, C. \& Keyes, C. L. M. (1995). The structure of psychological well-being revisited. Journal of Personality and Social Psychology, 69, 719-727. DOI:10.1037/00223514.69.4.719

Sexism cited in reaction to Stronach move (2005). Cbc.ca Retrieved July 2014 from http://www.cbc.ca/news/canada/sexism-cited-in-reaction-to-stronach-move1.547498

Schmitt, M. T., Branscombe, N. R., Kobrynowicz, D., \& Owen, S. (2002). Perceiving discrimination against one's gender group has different implications for well-being in women and men. Personality and Social Psychology Bulletin, 28, 197-210. DOI: $10.1177 / 0146167202282006$

Schmitt, M. T., Branscombe, N. R., Postmes, T., \& Garcia, A. (2014, February 17). The Consequences of Perceived Discrimination for Psychological Well-Being: A MetaAnalytic Review. Psychological Bulletin. Advance online publication. DOI:

10.1037/a0035754

Schulz, U. \& Schwarzer, R. (2003). Soziale Unterstützung bei der Krankheitsbewältigung. Die Berliner Social Support Skalen (BSSS) [Social support in coping with illness: The Berlin Social Support Scales (BSSS)]. Diagnostica, 49, 73-82.

Schwartz, L., \& Drotar, D. (2004). Linguistic analysis of written narratives of caregivers of children and adolescents with chronic illness: Cognitive and emotional processes and physical and psychological health outcomes. Journal of Clinical 
Psychology in Medical Settings, 11 , 291-301. DOI:

10.1023/B:JOCS.0000045349.10034.62

Shelton, J. N., \& Stewart, B. (2004). Confronting perpetrators of prejudice: The inhibitory effects of social costs. Psychology of Women, 28, 215-223.

DOI:10.1111/j.1471-6402.2004.00138.x

Sherbourne, C. D., Allen, H., Kamberg, C., \& Wells, K. B. (1992).

Physical/psychophysiologic symptoms measure. In A. L. Stewart \& J. E. Ware (Eds.), Measuring functioning and well-being: The medical outcomes study approach (pp. 260-276). Durham: Duke University Press.

Skinner, B. F. (1971). Beyond freedom and dignity. New York, NY, USA:Knopf.

Stroebe, K., Barreto, M., \& Ellemers, N. (2010). When searching hurts: The role of information search in reactions to gender discrimination. Sex Roles, 62, 60-76. DOI: 10.1007/s11199-009-9700-y

Stroebe, W., \& Stroebe, M. (1996). The social psychology of social support. In E. T. Higgins and A. W. Kruglanski (Eds.) Social Psychology: Handbook of Basic Principles (pp. 597-621). New York, NY, US: Guilford Press.

Tabachnick, B. G., \& Fidell, L. S. (2007). Using multivariate statistics. Boston, MA: Allyn \& Bacon.

Tajfel, H. \& Turner, J. (1986). The social identity theory of intergroup behavior. In S. Worchel and L. Austin (Eds.), Psychology of Intergroup Relations (pp. 7-24). Chicago: Nelson-Hall.

Tausch, N. \& Becker, J. C. (2013). Emotional reactions to success and failure of collective action as predictors of future action intentions: A longitudinal investigation in the 
context of student protests in Germany. British Journal of Social Psychology, 52, 525-542. DOI:10.1111/j.2044-8309.2012.02109.x

Tausczik, Y. R., \& Pennebaker, J. W. (2010). The psychological meaning of words: LIWC and computerized text analysis methods. Journal of Language and Social Psychology, 29, 24-54. DOI: 10.1177/0261927X09351676

"The top 500 sites on the web". Retrieved November 1, 2014 from alexa.com/topsites.

Tice, D. M. (1992). Self-concept change and self-presentation: The looking glass self is also a magnifying class. Journal of Personality and Social Psychology, 63, 435451. DOI: $10.1037 / / 0022-3514.63 .3 .435$

Tufekci, Z., \& Wilson, C. (2012). Social media and the decision to participate in political protest: Observations from Tahrir square. Journal of Communication, 62, 363-379 DOI:10.1111/j.1460-2466.2012.01629.x

Tumasjan, A., Sprenger, T., Sandner, P., \& Welpe, I. (2011). Election forecasts with Twitter: How 140 characters reflect the political landscape. Social Science Computer Review, 29, 402-418. DOI: 10.1177/0894439310386557

Van Zomeren, M., Drury, J., \& Van der Staaij. M. (2012). Experimental evidence for the empowering consequences of collective action. Manuscript submitted for publication.

Van Zomeren, M., \& lyer, A. (2009). Introduction to the social and psychological dynamics of collective action. Journal of Social Issues, 65, 645-660. DOI: /10.1111/j.15404560.2009.01618.x

Van Zomeren, M., Postmes, T., \& Spears, R. (2008). Toward an integrative Social Identity Model of Collective Action: A quantitative research synthesis of three 
socio-psychological perspectives. Psychological Bulletin, 134, 504-535. DOI:

$10.1037 / 0033-2909.134 .4 .504$

Vitak, J., Zube, P., Smock, A., Carr, C. T., Ellison, N., \& Lampe, C. (2011). It's complicated: Facebook users' political participation in the 2008 election. Cyberpsychology, behavior and social networking, 14, 107-114, DOI: 10.1089/cyber.2009.0226

Watson, D., \& Clark, L. A. (1994). The PANAS-X: The Manual for the positive and negative affect scale-Expanded form. Unpublished manuscript. University of lowa, lowa City, IA.

Weinberg, Z. (2005, September 21). A gentleman's guide to getting laid at WLU. The Cord Weekly, pp. 20-21.

Wright, S. C. (2009). The next generation of collective action research. Journal of Social Issues, 65, 859-879. DOI: 10.1111/j.1540-4560.2009.01628.x 
Figure 1

Interaction between Tweet condition and Day on Hostility

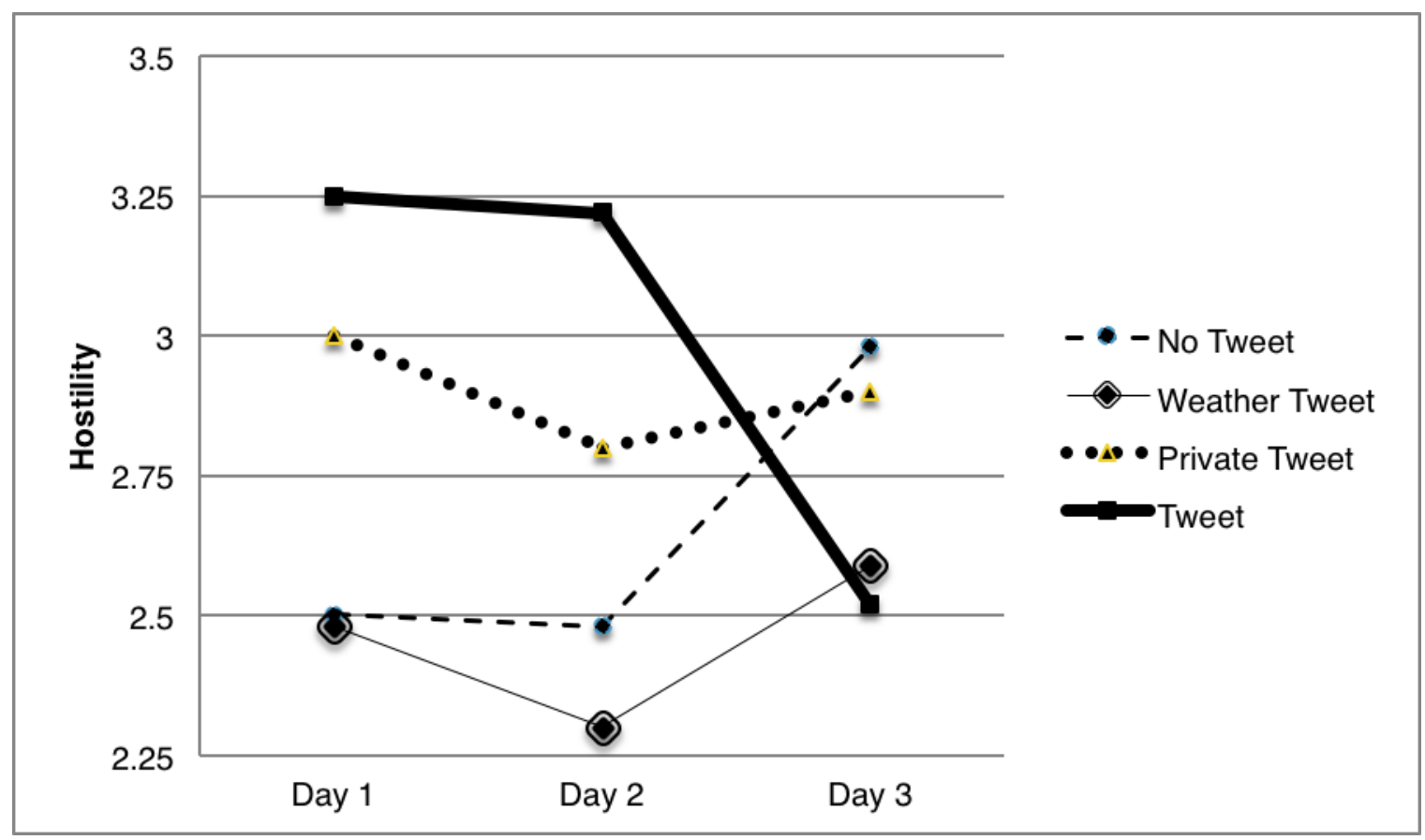


Figure 2

Interaction between Tweet condition and Day on Sadness

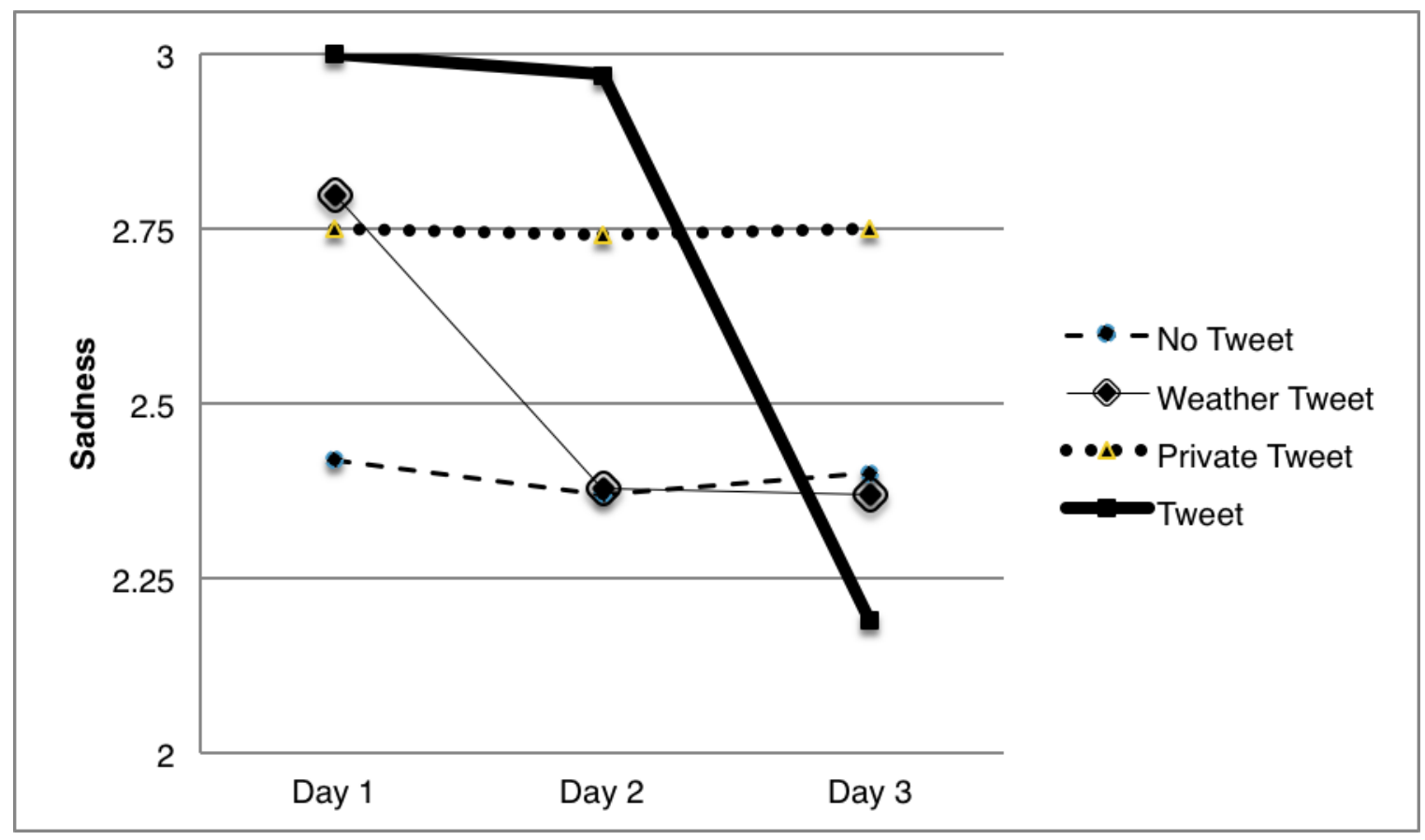


Figure 3

Interaction between Tweeting condition and Day on Psychological well-being

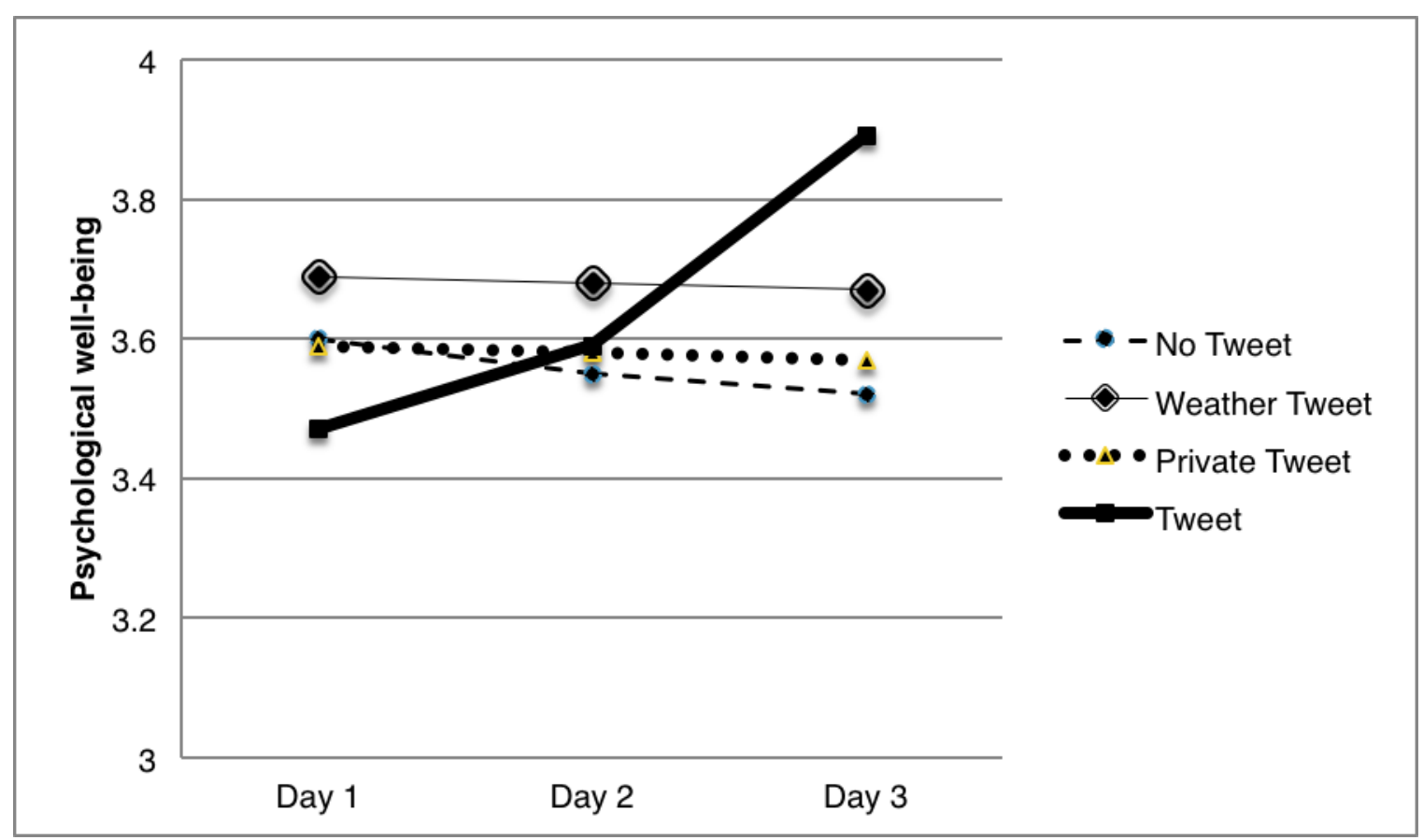

